\title{
Optimum take-off angle in the long jump
}

\author{
NICHOLAS P. LINTHORNE ${ }^{1}$, MAURICE S. GUZMAN² , \& LISA A. BRIDGETT ${ }^{3}$ \\ ${ }^{1}$ Department of Sport Sciences, Brunel University, Uxbridge, Middlesex, UK \\ ${ }^{2}$ School of Physiotherapy, The University of Sydney, Lidcombe, NSW, Australia \\ ${ }^{3}$ School of Exercise and Sport Science, The University of Sydney, Lidcombe, NSW, Australia
}

\begin{abstract}
In this study, we found that a long jumper's optimum take-off angle may be predicted by combining the equation for the range of a projectile in free flight with the measured relations between take-off speed, take-off height and take-off angle for the athlete. The prediction method was evaluated using high-speed video measurements of three experienced male long jumpers who performed maximumeffort jumps over a wide range of take-off angles. To produce low take-off angles the athletes used a long and fast run-up, whereas higher take-off angles were produced using a progressively shorter and slower run-up. For all three athletes, the take-off speed decreased and the take-off height increased as the athlete jumped with a higher take-off angle. The calculated optimum take-off angles were in good agreement with the athletes' competition take-off angles.
\end{abstract}

Keywords:

athletics, long jump, projectile, sports biomechanics, take-off angle.

Corresponding Author: ～N. P. Linthorne, Email: nick.linthorne@brunel.ac.uk

\section{Introduction}

Long jumpers try to project their body for maximum horizontal distance beyond a take-off line. Whilst in the air the athlete is essentially a projectile in free flight and so the flight distance achieved is determined by the conditions at take-off. It is generally recognised that a high take-off speed is essential for a good performance and that the jumper benefits from having a high position of the centre of mass at take-off (Hay, 1993). However, the optimum take-off angle that produces the greatest jump distance is not well understood. Differentiation of the equation for the range of a projectile in free flight, followed by substitution of measured values of the take-off speed and take-off height, gives an incorrect optimum take-off angle of about $43^{\circ}$ (de Mestre 1990; Hay, 1993). Tan and Zumerchik (2000) calculated the optimum take-off angle by assuming that the jumper loses a constant fraction of their translational kinetic energy at take-off. However, they did not provide compelling evidence for this assumption, and the predicted optimum take-off angle for a top male jumper (about $\left.33^{\circ}\right)$ is considerably greater than observed values for world-class long jumpers $\left(15^{\circ}-27^{\circ}\right)$ 
(Arampatzis, Brüggemann, \& Walsch, 1999; Hay, Miller, \& Cantera, 1986; Lees, Fowler, \& Derby, 1993; Lees, Graham-Smith, \& Fowler, 1994; Nixdorf \& Brüggemann, 1988, 1990).

A promising approach for calculating the optimum take-off angle is the method used by Red and Zogaib (1977) in an analysis of the javelin throw. They recognized that the release speed and release angle are not independent quantities and that their inter-relation must be included in the calculation of the optimum release angle. In a study of three male javelin throwers, Red and Zogaib observed a linear decrease in release speed with increasing release angle. The optimum release angle was calculated by combining the measured relation between release speed and release angle for the athlete with the equations describing the trajectory of the javelin in the flight phase. For the most experienced participant in the study the calculated optimum release angle $\left(37^{\circ}\right)$ was in good agreement with measured release angles of world-class javelin throwers (35-38º).

Linthorne (2001) used a similar method to calculate the optimum release angle in the shot put. He analysed data reported by Maheras (1995) for five college shot-putters who performed maximumeffort throws over a wide range of release angles. The shot-putters' release speed decreased with increasing release angle because a greater fraction of muscular force is required to overcome the weight of the shot and because the structure of the human body favours the production of putting force in the horizontal direction more than in the vertical direction. Linthorne's calculations included the relation between the release height and release angle, as well as between the release speed and release angle. The calculated optimum release angles for the athletes were in good agreement with their usual competition release angles $\left(31-35^{\circ}\right)$. Each athlete had his own specific optimum release angle because of individual differences in the rate of decrease in release speed with increasing release angle.

In the present study, the optimum take-off angle in the long jump was calculated using a method similar to that used by Linthorne (2001) for the shot put. The method was evaluated using measurements of three experienced male long jumpers who performed maximum-effort jumps over a wide range of take-off angles. The optimum take-off angle of each jumper was calculated by combining the equation for the flight distance of a body in free flight with the observed relations between the take-off speed, the height difference between take-off and landing, and the take-off angle for the athlete. The calculated optimum take-off angle was then compared with the athlete's measured competition take-off angles.

\section{Component Distances}

Long jump performance is quantified by the official distance, $d_{\text {official}}$, which is the distance from the take-off line to the nearest break in the landing area made by any part of the body or limbs. The official distance may be considered as the sum of the take-off distance, $d_{\text {take-off, the flight distance, }}$

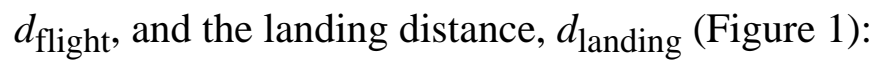

$$
d_{\text {official }}=d_{\text {take-off }}+d_{\text {flight }}+d_{\text {landing }}
$$


The take-off distance is the horizontal distance between the take-off line and the athlete's centre of mass at the instant of take-off; the flight distance is the horizontal distance the athlete's centre of mass travels from the instant of take-off to the instant of landing; and the landing distance is the horizontal distance between the athlete's centre of mass at the instant of landing and the break in the landing area nearest to the take-off line. In performances by world-class long jumpers, the flight distance is a large fraction of the official distance (about 90\%), whereas the take-off and landing distances make only relatively small contributions (about 5\% each) (Hay et al., 1986). Because the flight distance is such a large fraction of the official distance, the take-off angle that maximises the flight distance is expected to be very nearly the same as that which maximises the official distance.

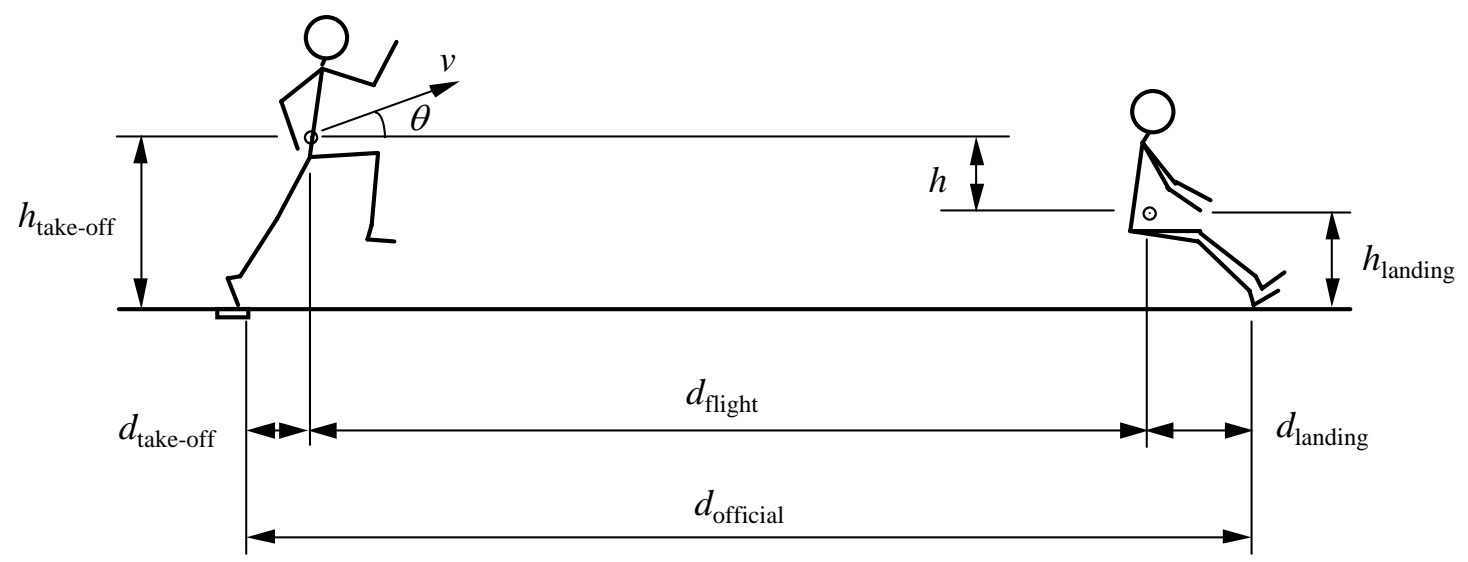

Figure 1. Diagram of a long jump showing contributions to the official distance.

\section{Flight distance}

During the flight phase of the jump, the effects of gravity are much greater than those of aerodynamic forces, and so the jumper may be considered as a body in free flight (Ward-Smith, 1985). The flight distance of a long jumper is then given by (de Mestre, 1990; Hay, 1993; Hubbard, 2001):

$$
d_{\text {flight }}=\frac{v^{2} \sin 2 \theta}{2 g}\left[1+\left(1+\frac{2 g h}{v^{2} \sin ^{2} \theta}\right)^{1 / 2}\right]
$$

where $v$ is the take-off speed, $\theta$ is the take-off angle and $g$ is the acceleration due to gravity. The relative take-off height, $h$, is given by:

$$
h=h_{\text {take-off }}-h_{\text {landing }}
$$

where $h_{\text {take-off }}$ is the take-off height and $h_{\text {landing }}$ is the landing height (Figure 1). When $h=0$, equation (2) reduces to the familiar expression for the range of a projectile launched from ground level over a horizontal plane, $d_{\text {flight }}=\left(v^{2} \sin 2 \theta\right) / g$.

If the take-off speed and relative take-off height are independent of the take-off angle, the takeoff angle that maximises the flight distance may be found by differentiating equation (2) with respect 
to $\theta$, and setting the resulting expression equal to zero (de Mestre, 1990; Hubbard, 2001; Lichtenberg \& Wills, 1978). For a typical take-off speed of $8.5-10.0 \mathrm{~m} \cdot \mathrm{s}^{-1}$ and a relative take-off height of $0.6 \mathrm{~m}$, this gives a predicted optimum take-off angle of about $43^{\circ}$ (Hay, 1993). This result is clearly incorrect. Both take-off velocity and relative take-off height are expected to depend on the take-off angle used by the athlete (de Mestre, 1990; Hay, 1993), and so equation (2), by itself, is insufficient to calculate the optimum take-off angle in the long jump.

\section{Methods}

In this study, the optimum take-off angle for the athlete was calculated by combining the equation for the flight distance of a body in free flight (equation 2) with the athlete's relations between the take-off speed and take-off angle, $v(\theta)$, and between relative take-off height and take-off angle, $h(\theta)$. This method required intervention by the investigator to obtain measurements of the athlete's take-off speed and relative take-off height over a wide range of take-off angles, rather than just at the athlete's competition take-off angle. The measurements of take-off speed and relative take-off height were plotted as a function of the take-off angle, and curves were fitted to give algebraic expressions for $v(\theta)$ and $h(\theta)$. The expressions for $v(\theta)$ and $h(\theta)$ were then substituted into equation (2).

A refinement to Linthorne's (2001) method used in this study was to include the influence of the take-off and landing distances on the optimum take-off angle (Figure 1). The relation between take-off distance and take-off angle, $d_{\text {take-off }}(\theta)$, was determined, as was the relation between landing distance and take-off angle, $d_{\text {landing }}(\theta)$. These relations were included in the calculation of the optimum take-off angle through equation (1). The official distance was plotted as a function of the take-off angle, and the optimum take-off angle was the point on the curve at which the official distance was greatest.

In this study, the mathematical expressions for $v(\theta), h(\theta), d_{\text {take-off }}(\theta)$, and $d_{\text {landing }}(\theta)$ were obtained by fitting mathematical relations to plots of take-off speed, relative take-off height, take-off distance and landing distance as a function of take-off angle. The selected mathematical relation was one with a similar shape to the experimental data and with only a few fitted parameters so as to minimize the uncertainty associated with the fitted parameter values. A more illuminating method of curve fitting would be to derive the fitted mathematical expressions from physical models, with $v(\theta)$, $h(\theta), d_{\text {take-off }}(\theta)$, and $d_{\text {landing }}(\theta)$ being used to evaluate the models (Linthorne, 2001). The simple model of jumping used by Alexander (1990) shows promise in predicting these relations, but such a study is a considerable undertaking and not even necessary for the purposes of the present study as the desired relations may be obtained empirically.

In examining the optimum take-off angle in the long jump, this study used measurements of three male long jumpers. The athletes were highly experienced, and so it was assumed that their competition take-off angles would be very close to their optimum take-off angle. The accuracy of the method of calculating the optimum take-off angle was assessed by comparing the athlete's calculated optimum take-off angle with their measured competition take-off angles. 


\section{Measurements of the take-off phase}

The relations between the take-off variables were measured for three experienced male long-jumpers. The study was approved by the Human Ethics Committee of the University of Sydney, the participants were informed of the protocol and procedures prior to their involvement, and written consent to participate was obtained.

Table I lists the height, mass and competition best-performance (with legal wind) of the three athletes. The athletes jumped in regular long jump pits that had a synthetic all-weather runway and a standard wooden take-off board. Athlete 1 was recorded at four competition and ten training sessions, for a total of 92 jumps. In the competition sessions and in some training sessions, no direct intervention was used and the athlete jumped at his 'normal' take-off angle by using his usual competition run-up length and run-up speed. Two intervention sessions were used in which the athlete was instructed to jump at angles that were 'low', 'high' and 'very high' compared to his normal competition take-off angle. The athlete performed the jumps using a self-selected run-up length and run-up speed. The jumps at low take-off angles $\left(0-30^{\circ}\right)$ were produced using a long (1420 strides) and fast $\left(9.5-11.0 \mathrm{~m} \cdot \mathrm{s}^{-1}\right)$ run-up. Higher take-off angles were produced using a progressively shorter and slower run-up.

Table I. Height, mass and best competition performance (with legal wind) for the three athletes in the study.

\begin{tabular}{cccc}
\hline Athlete & Height $(\mathrm{m})$ & Mass $(\mathrm{kg})$ & Best performance $(\mathrm{m})$ \\
\hline 1 & 1.88 & 80 & 8.30 \\
2 & 1.80 & 61 & 7.94 \\
3 & 1.75 & 62 & 7.58 \\
\hline
\end{tabular}

A JVC GR-DVL9800 high-speed video camera operating at $100 \mathrm{~Hz}$ was used to record the jumps. The camera was placed between 15 and $25 \mathrm{~m}$ from the middle of the long jump runway, with the optical axis of the camera perpendicular to the long jump runway and in line with the front edge of the take-off board. The field of view of the camera was zoomed so that the athlete was visible from the first contact of the last stride before take-off, through to about $4 \mathrm{~m}$ after take-off. The movement space was calibrated with two 2.10 -m high poles that were placed along the midline of the runway and 3.0 to $5.2 \mathrm{~m}$ apart. The wind velocity was measured for all of the competition jumps, and performances in which the wind velocity was not between $-2 \mathrm{~m} \cdot \mathrm{s}^{-1}$ and $+2 \mathrm{~m} \cdot \mathrm{s}^{-1}$ were excluded from the analysis.

An Ariel Performance Analysis System was used to analyse the video images of the jumps. Sixteen body landmarks that defined a 16-segment model of the athlete were digitised in each image. The segmental data used were those proposed by Dempster (1955) for male adults, and the twodimensional coordinates of the body landmarks and the athlete's centre of mass were calculated from 
the digitised data using the direct linear transform (DLT) algorithm. Coordinate data were smoothed using a second-order Butterworth digital filter with a cut-off frequency of $10 \mathrm{~Hz}$, and the velocity of the athlete's centre of mass was calculated by direct differentiation of the coordinate data. The choice of cut-off frequency was based on a residual analysis (Winter, 1990) and a visual inspection of the power spectra of the coordinate and velocity data.

The instant of take-off was defined as the first clear frame in which the take-off foot was observed to break contact with the ground (Hay et al., 1986; Lees et al., 1994). The athlete's take-off speed and take-off angle were calculated from the horizontal and vertical speed of the athlete's centre of mass at the instant of take-off, and the take-off height and take-off distance were the vertical and horizontal distances of the athlete's centre of mass relative to the take-off line.

Similar protocols were used for Athletes 2 and 3. Athlete 3 jumped a total of 50 times in three competitions and two training sessions. Athlete 2 jumped 13 times in each of two training sessions, for a total of 26 jumps. Four of the jumps by Athlete 2 were simulated competition jumps, where the athlete attempted to jump for maximum horizontal distance using his usual competition run-up length and run-up speed. All jumps by Athlete 2 were recorded with a Panasonic HQ-NVM7 video camera operating at $50 \mathrm{~Hz}$, and smoothing of raw data from the digitising process was performed using a cutoff frequency of $5 \mathrm{~Hz}$. Wind readings were not recorded, but an experienced athletics observer estimated the wind to be between $-2 \mathrm{~m} \cdot \mathrm{s}^{-1}$ and $+2 \mathrm{~m} \cdot \mathrm{s}^{-1}$ on all jumps during the two filming sessions.

In this study, the measurement uncertainties were assumed to be similar to the uncertainties reported by Lees et al. (1993) for a study of the long jump take-off that used a similar experimental method and analysis procedure. They calculated the average variation in values obtained by four different experimenters who each digitised a selection of four jumps. In the present study, the estimated uncertainties for Athlete 1 and 3 are about 4\% for take-off speed, 9\% for take-off angle, and $2 \%$ for take-off height and take-off distance. The uncertainties for Athlete 2 are expected to be slightly greater because of the lower sampling frequency (Graham-Smith \& Lees, 1997).

\section{Results}

Table II lists the average official distance, take-off speed, take-off angle, take-off height, and take-off distance for the competition jumps (and simulated competition jumps). These values are consistent with data for experienced male long jumpers (Arampatzis et al., 1999; Hay et al., 1986; Lees et al., 1994; Nixdorf \& Brüggemann, 1988, 1990). Figures 2, 3 and 4 show the take-off speed, take-off height and take-off distance as a function of the take-off angle for the best-performing athlete (Athlete 1). Plots similar to those in Figures 2, 3 and 4 were obtained for Athletes 2 and 3. 
Table II. Take-off parameters for the competition jumps (mean $\pm s$ ).

\begin{tabular}{|c|c|c|c|c|c|c|}
\hline Athlete & $\begin{array}{l}\text { Number } \\
\text { of jumps }\end{array}$ & $\begin{array}{c}\text { Official } \\
\text { distance } \\
d_{\text {official }} \\
\text { (m) }\end{array}$ & $\begin{array}{c}\text { Take-off } \\
\text { speed } \\
v \\
\left(\mathrm{~m} \cdot \mathrm{s}^{-1}\right)\end{array}$ & $\begin{array}{c}\text { Take-off } \\
\text { angle } \\
\theta \\
\left(^{\circ}\right)\end{array}$ & $\begin{array}{l}\text { Take-off } \\
\text { height } \\
h_{\text {take-off }} \\
\text { (m) }\end{array}$ & $\begin{array}{l}\text { Take-off } \\
\text { distance } \\
d_{\text {take-off }} \\
\text { (m) }\end{array}$ \\
\hline 1 & 23 & $7.89 \pm 0.16$ & $9.56 \pm 0.43$ & $21.4 \pm 1.6$ & $1.20 \pm 0.04$ & $0.44 \pm 0.06$ \\
\hline 2 & 4 & $7.80 \pm 0.26$ & $9.78 \pm 0.26$ & $23.5 \pm 1.0$ & $1.25 \pm 0.01$ & $0.36 \pm 0.04$ \\
\hline 3 & 12 & $7.05 \pm 0.17$ & $8.70 \pm 0.26$ & $22.7 \pm 0.5$ & $1.10 \pm 0.02$ & $0.45 \pm 0.02$ \\
\hline
\end{tabular}

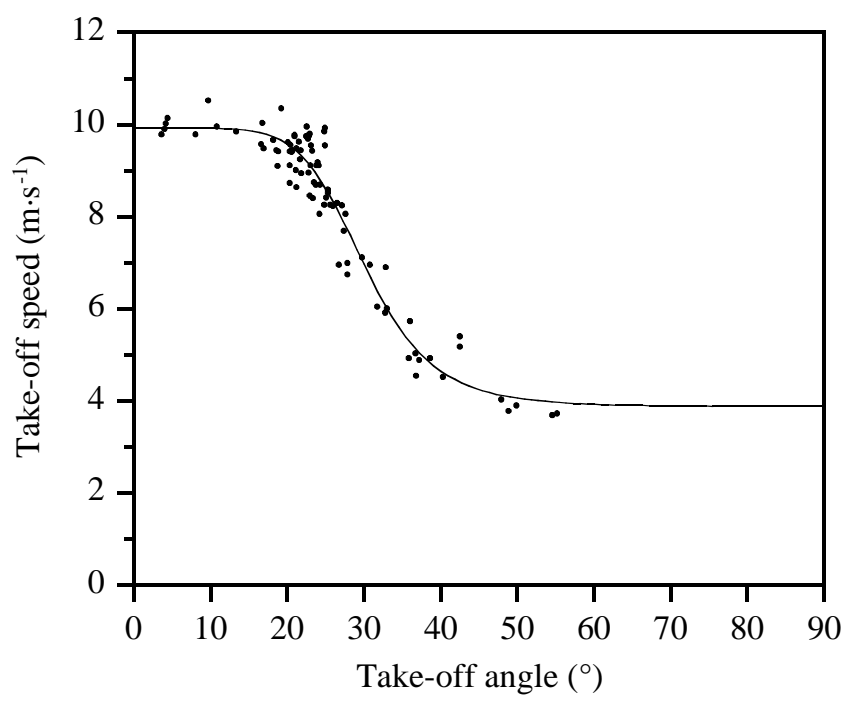

Figure 2. Take-off speed decreased with increasing take-off angle. To produce a low take-off angle the jumper used a long and fast run-up and did not jump upwards much at take-off. Higher take-off angles required a progressively slower run-up speed to allow the jumper to produce the necessary balance between vertical takeoff speed and horizontal take-off speed. (Data for an experienced male long-jumper, Athlete 1)

\section{Take-off speed}

The greatest take-off speed a jumper can produce is in a 'run-through', where the athlete approaches the take-off board at maximum speed but does not jump up at take-off. To increase the take-off angle above zero, the jumper must produce vertical speed. At touchdown, the jumper plants his take-off foot ahead of his centre of mass, thus allowing a greater ground contact time in which to generate vertical impulse (force integrated over time). However, this vertical impulse comes at the expense of a horizontal braking impulse, and so the resultant take-off speed is reduced. To produce take-off angles of greater than about $30^{\circ}$, the jumper must use a sub-maximal run-up speed so as to give sufficient ground contact time to produce the desired vertical speed. Higher take-off angles require a progressively slower run-up speed, with a vertical take-off angle being performed from a run-up of two strides or less. 


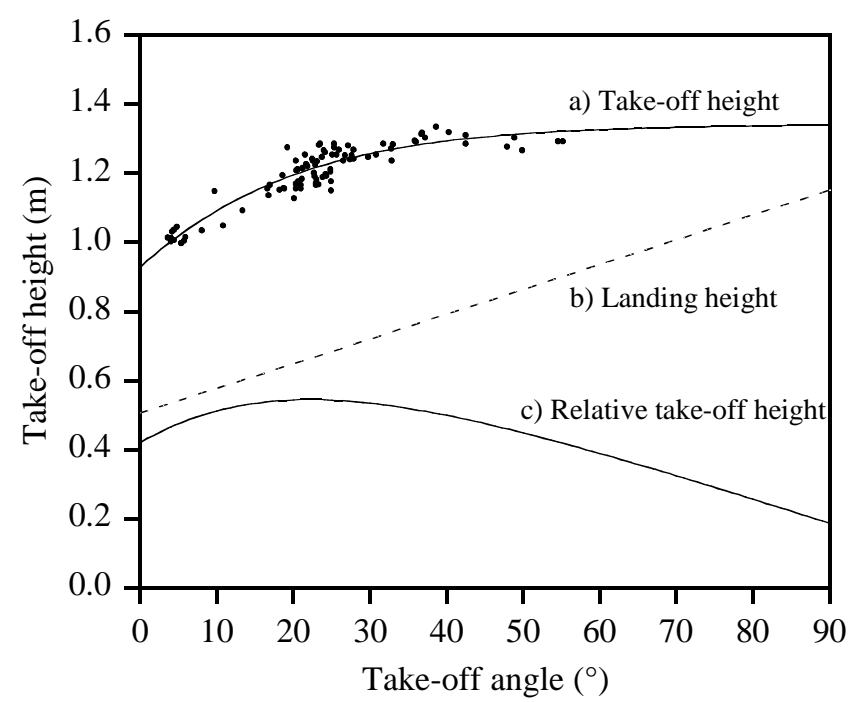

Figure 3. (a) Take-off height increased with increasing take-off angle. (Data for Athlete 1.) When jumping at lower take-off angles, the athlete moved his trunk farther ahead of his take-off foot, the take-off leg made a lesser angle to the horizontal, and the height of the athlete's centre of mass was consequently reduced. (b) The dashed line shows the assumed relation between landing height and take-off angle. When jumping at lower takeoff angles, the athlete had a higher horizontal speed at landing and so he could land in a lower position with his feet far ahead of his body without the risk of falling backward after landing. (c) The relative take-off height is the difference between the take-off height and the landing height

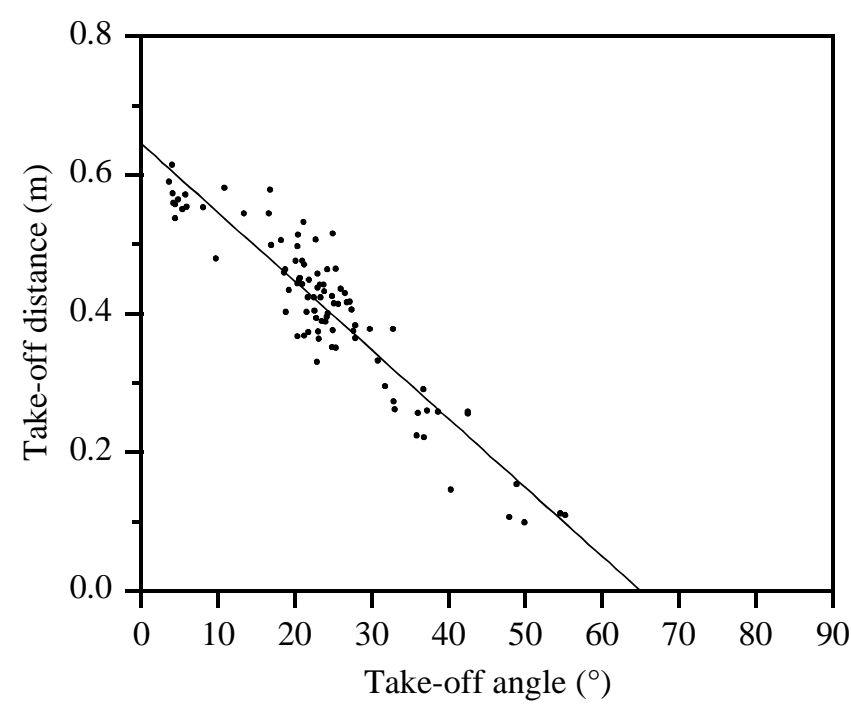

Figure 4. Take-off distance decreased with increasing take-off angle. (Data for Athlete 1.) When jumping at lower take-off angles, the athlete moved his trunk farther ahead of his take-off foot, the take-off leg made a lesser angle to the horizontal, and the take-off distance was consequently increased.

The plots of take-off speed versus take-off angle (Figure 2) suggested a relation of the form of a symmetric logistic function (also called a symmetric sigmoid): 


$$
v(\theta)=\frac{v_{\max }-v_{\min }}{1+\left(\frac{\theta}{\theta_{\mathrm{inf}}}\right)^{a}}+v_{\min }
$$

where $v_{\max }$ is the asymptotic maximum take-off speed (as in a run-through, where $\theta \approx 0^{\circ}$ ), $v_{\min }$ is the asymptotic minimum take-off speed (as in an upwards vertical jump from one leg, where $\theta \approx 90^{\circ}$ ), $\theta_{\text {inf }}$ is the value of the take-off angle at the inflection point of the curve, and $a$ is the slope coefficient. A curve of the form of equation (4) was fitted to a plot of the athlete's take-off speed as a function of take-off angle by selecting values of $v_{\max }, v_{\min }, a$ and $\theta_{\text {inf }}$ using the Levenberg-Marquardt algorithm (Press, Flannery, Teukolsky, \& Vetterling, 1988). Table III lists the calculated values of $v_{\max }, v_{\min }, a$ and $\theta_{\text {inf }}$, and Figure 2 shows the fitted curve for Athlete 1 . The calculated values of $v_{\max }$ are consistent with measurements of the horizontal speed of the athlete in the last stride before take-off for jumps from a full-length run-up, and the calculated values of $v_{\min }$ are consistent with measurements of the vertical take-off speed of athletes performing a standing vertical jump.

Table III. Parameter values obtained from fitting equation (4) to plots of the take-off speed as a function of take-off angle (value \pm standard error).

\begin{tabular}{ccccc}
\hline Athlete & $\begin{array}{c}\text { Maximum take- } \\
\text { off speed } \\
v_{\text {max }} \\
\left(\mathrm{m} \cdot \mathrm{s}^{-1}\right)\end{array}$ & $\begin{array}{c}\text { Minimum take- } \\
\text { off speed } \\
v_{\text {min }} \\
\left(\mathrm{m} \cdot \mathrm{s}^{-1}\right)\end{array}$ & $\begin{array}{c}\text { Slope coefficient } \\
a\end{array}$ & $\begin{array}{c}\text { Angle of } \\
\text { inflection point } \\
\theta_{\text {inf }} \\
\left({ }^{\circ}\right)\end{array}$ \\
\hline 1 & $9.9 \pm 0.1$ & $3.9 \pm 0.2$ & $6.8 \pm 0.7$ & $30.2 \pm 0.6$ \\
2 & $10.7 \pm 0.5$ & $3.1 \pm 0.4$ & $4.0 \pm 0.8$ & $36.8 \pm 1.5$ \\
3 & $8.8 \pm 0.1$ & $3.9 \pm 1.1$ & $6.0 \pm 1.4$ & $38.2 \pm 2.9$ \\
\hline
\end{tabular}

\section{Take-off height}

The height of the jumper's centre of mass at take-off is determined by his body position. When jumping with a vertical $\left(90^{\circ}\right)$ take-off angle, the jumper extends his take-off leg straight up and lifts his free knee up to about the level of the hips. When jumping at lower take-off angles, the athlete moves his trunk farther ahead of his take-off foot, the take-off leg makes a lesser angle to the horizontal, and the height of the athlete's centre of mass is consequently reduced (Figure 1).

The plots of take-off height versus take-off angle (Figure 3) suggested a relation of the form of the Gompertz growth equation:

$$
h_{\text {take-off }}=h_{\max } e^{\left(-A_{1} e^{-A_{2} \theta}\right)}
$$


where $h_{\max }$ is the asymptotic maximum height of the jumper's centre of mass at take-off (as in an upwards vertical jump from one leg, where $\left.\theta \approx 90^{\circ}\right), A_{1}$ is a constant that determines the height of the jumper's centre of mass in a run-through (where $\theta \approx 0^{\circ}$ ) and $A_{2}$ is the growth rate coefficient. A curve of the form of equation (5) was fitted to a plot of the athlete's take-off height as a function of take-off angle by selecting values of $h_{\max }, A_{1}$ and $A_{2}$ using the Levenberg-Marquardt algorithm (Press et al., 1988). Table IV lists the calculated values of $h_{\max }, A_{1}$ and $A_{2}$, and Figure 3 shows the fitted curve for Athlete 1 . When jumping vertically upwards, the body position adopted at take-off by the athletes was similar to that of a high jumper at take-off. The athletes in the present study had $h_{\max }$ values of $71-80 \%$ of their standing height, which is consistent with the take-off height reported for high jumpers (Dapena, McDonald, \& Cappaert, 1990).

Table IV. Parameter values obtained from fitting equation (5) to plots of the take-off height as a function of take-off angle (value \pm standard error).

\begin{tabular}{|c|c|c|c|}
\hline Athlete & $\begin{array}{l}\text { Maximum centre of } \\
\text { mass height } \\
h_{\max } \\
(\mathrm{m})\end{array}$ & $\begin{array}{c}\text { Zero take-off angle } \\
\text { coefficient } \\
A_{1}\end{array}$ & $\begin{array}{c}\text { Growth rate } \\
\text { coefficient } \\
A_{2} \\
\text { (degree }^{-1} \text { ) }\end{array}$ \\
\hline 1 & $1.34 \pm 0.02$ & $0.37 \pm 0.02$ & $0.058 \pm 0.007$ \\
\hline 2 & $1.29 \pm 0.01$ & $0.20 \pm 0.02$ & $0.070 \pm 0.010$ \\
\hline 3 & $1.40 \pm 0.05$ & $0.51 \pm 0.03$ & $0.035 \pm 0.006$ \\
\hline
\end{tabular}

\section{Relative take-off height}

In the long jump, the flight distance is determined by the relative take-off height, which is the height difference between the take-off and the landing. In this study, the landing phase of the jump was not recorded and so the landing height could not be determined. However, the landing phase in a long jump is similar to that in a standing long jump. Wakai and Linthorne (2002) analysed the landing phase of five adult male participants who performed maximum-effort standing long jumps for distance using a wide range of take-off angles $\left(20-90^{\circ}\right)$. They observed a linear increase in landing height with increasing take-off angle, from about $60 \mathrm{~cm}$ at $20^{\circ}$ to about $110 \mathrm{~cm}$ at $90^{\circ}$. The landing technique used by a jumper is determined by the requirement to maintain balance during the landing. When jumping at low takeoff angles, an athlete has a high horizontal speed at landing and so he can land with his feet far ahead of his body without the risk of falling backward after landing (Figure 1). When landing from a high takeoff angle, the athlete has a lower horizontal speed and so lands in a nearly upright position with the feet only slightly ahead of the body. The height of the athlete's centre of mass at landing therefore steadily increases as the take-off angle is increased.

A relation between landing height and take-off angle similar to that observed by Wakai and Linthorne (2002) was assumed for the athletes in the present study (Figure 3). It is reasonable to 
expect the landing height to scale in direct proportion to the athlete's standing height. The relative take-off height (equation 3) is then given by:

$$
h(\theta)=h_{\max } e^{\left(-A_{1} e^{-A_{2} \theta}\right)}-l\left(B_{1}+B_{2} \theta\right)
$$

where $B_{1}=0.27, B_{2}=0.0038$ degree $^{-1}$ and $l$ is the height of the athlete (in metres). For the three jumpers in this study, the relative take-off height was approximately constant $(h \approx 45-65 \mathrm{~cm})$ between 0 and $40^{\circ}$, and then steadily decreased to about zero for a vertical take-off (Figure 3).

\section{Take-off distance}

The take-off distance is determined by the jumper's body position at take-off and by the proximity of his take-off foot to the take-off line. When jumping with a vertical $\left(90^{\circ}\right)$ take-off angle, the jumper extends his take-off leg straight up, and so his centre of mass is nearly aligned with his take-off foot. When jumping at lower take-off angles, the athlete moves his trunk farther ahead of his take-off foot, the take-off leg makes a lesser angle to the horizontal, and the take-off distance is consequently increased.

The plots of take-off distance versus take-off angle (Figure 4) suggested a linear relation that scales in proportion to the athlete's standing height:

$$
d_{\text {take-off }}(\theta)=l\left(C_{1}-C_{2} \theta\right)
$$

where $C_{1}$ is the normalised maximum take-off distance (as in a run-through, where $\theta \approx 0^{\circ}$ ), and $C_{2}$ is a constant that determines the rate of decrease in take-off distance with increasing take-off angle. A curve of the form of equation (7) was fitted to a plot of the athlete's take-off distance as a function of take-off angle by selecting values of $C_{1}$ and $C_{2}$ using the Levenberg-Marquardt algorithm (Press et al., 1988). Table $\mathrm{V}$ lists the calculated values of $C_{1}$ and $C_{2}$, and Figure 4 shows the fitted curve for Athlete 1 . The linear relation only applies to jumps with a take-off angle below about $60^{\circ}$. When jumping with a higher take-off angle, the centre of mass of the athlete tended to be aligned with the toe of the take-off foot, and so $d_{\text {take-off }} \approx 0$.

\section{Landing distance}

In this study, the landing phase of the jump was not recorded and so the landing distance could not be determined. In Wakai and Linthorne's (2002) analysis of the standing long jump, the participants showed a linear decrease in landing distance with increasing take-off angle, from about $20 \mathrm{~cm}$ at $20^{\circ}$ to about $0 \mathrm{~cm}$ at $90^{\circ}$. Again, the landing distance is determined by the jumper's body position. When jumping at low takeoff angles, an athlete has a high horizontal speed at landing and so he can land with his feet far ahead of his body without the risk of falling backward after landing. When landing from a high takeoff angle, the athlete has a lower horizontal speed and so lands in a nearly upright 
position with the feet only slightly ahead of the body. The landing distance therefore steadily decreases as the take-off angle is increased.

Table V. Parameter values obtained from fitting equation (7) to plots of the take-off distance as a function of take-off angle (value \pm standard error).

\begin{tabular}{ccc}
\hline Athlete & $\begin{array}{c}\text { Normalized } \\
\text { maximum take-off } \\
\text { distance } \\
C_{1}\end{array}$ & $\begin{array}{c}\text { Normalized rate of } \\
\text { decrease } \\
C_{2} \\
\left.\text { (degree }^{-1}\right)\end{array}$ \\
\hline 1 & $0.34 \pm 0.01$ & $0.0053 \pm 0.0002$ \\
2 & $0.31 \pm 0.03$ & $0.0058 \pm 0.0007$ \\
3 & $0.40 \pm 0.01$ & $0.0067 \pm 0.0003$ \\
\hline
\end{tabular}

The landing phase in a long jump is similar to that in a standing long jump, and so a similar relation between landing distance and take-off angle was assumed for the athletes in the present study. Again, it is reasonable to expect the landing distance to scale in direct proportion to the standing height of the athlete. The landing distance is then given by:

$$
d_{\text {landing }}(\theta)=l\left(D_{1}-D_{2} \theta\right)
$$

where $D_{1}=0.17, D_{2}=0.0020$ degree $^{-1}$ and $l$ is the height of the athlete (in metres).

\section{The optimum take-off angle}

The optimum take-off angle for each athlete was calculated and compared to their observed competition take-off angles. The values of $v_{\max }, v_{\min }, a$ and $\theta_{\text {inf }}$ for the athlete were substituted into equation (4), and the values of $h_{\max }, A_{1}$ and $A_{2}$ were substituted into equation (6). The resulting expressions for $v(\theta)$ and $h(\theta)$ were then substituted into equation (2) to give an expression for the flight distance, $d_{\text {flight }}$. The values of $C_{1}$ and $C_{2}$ for the athlete were substituted into equation (7) to give an expression for the take-off distance, $d_{\text {take-off, }}$ and the expression for the landing distance,

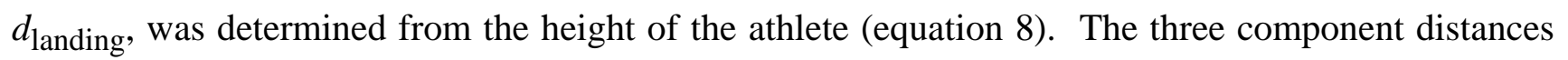
were added to give the official distance (equation 1), and the official distance was plotted as a function of the take-off angle. The optimum take-off angle was the point on the curve at which the official distance was greatest.

The calculated optimum take-off angles for the three athletes are listed in Table VI. The standard error associated with the calculated optimum take-off angle was determined using the quadrature method of combining errors (Taylor, 1997). For Athlete 2, the greater error associated with the fitted parameter values and the calculated optimum take-off angle is a reflection of the lower 
sampling frequency $(50 \mathrm{~Hz})$ used when filming the athlete. For all three athletes, the calculated optimum take-off angles were in good agreement with the measured competition take-off angles. Therefore, this investigation confirmed that a long jumper's optimum take-off angle may be calculated by combining the equation for the range of a projectile in free flight with the measured relations between the take-off speed, height and angle for the athlete.

Table VI. Comparison of the athlete's competition take-off angle with the calculated optimum take-off angle (value \pm standard error).

\begin{tabular}{ccc}
\hline Athlete & $\begin{array}{c}\text { Competition } \\
\text { take-off angle } \\
\left({ }^{\circ}\right)\end{array}$ & $\begin{array}{c}\text { Calculated optimum } \\
\text { take-off angle } \\
\left({ }^{\circ}\right)\end{array}$ \\
\hline 1 & $21.4 \pm 0.3$ & $20.9 \pm 0.7$ \\
2 & $23.5 \pm 0.5$ & $21.6 \pm 2.1$ \\
3 & $22.7 \pm 0.1$ & $25.4 \pm 1.6$ \\
\hline
\end{tabular}

The optimum take-off angle in the long jump may be explained as follows. For a projectile that is released with constant speed from ground level, the optimum projection angle that maximizes the flight distance is $45^{\circ}$. However, in long-jumping there are several additional effects that modify the optimum projection angle:

The take-off speed that the athlete is able to produce decreases with increasing take-off angle. For the long jumpers in this study, this lowered the optimum take-off angle by $18-23^{\circ}$.

The height of landing is lower than the take-off height, and the relative take-off height decreases with increasing take-off angle. This lowered the optimum take-off angle by a further 0.7$1.5^{\circ}$.

At the instant of take-off the jumper's centre of mass is in front of the take-off line, and this take-off distance decreases with increasing take-off angle. However, this had a relatively small effect on the optimum take-off angle; the optimum take-off angle was lowered by only about $0.2^{\circ}$.

The jumper breaks the landing area at a point in front of the jumper's centre of mass, and this landing distance decreases with increasing take-off angle. Again, this had a relatively small effect; the optimum take-off angle was lowered by only about $0.1^{\circ}$

Figure 5 illustrates how the relations for $v(\theta), h(\theta), d_{\text {take-off }}(\theta)$ and $d_{\text {landing }}(\theta)$ determine the optimum take-off angle. The change in the athlete's take-off speed with take-off angle, $v(\theta)$, had the greatest effect on the optimum take-off angle, and each athlete had his own specific optimum take-off angle because of individual differences in the rate of speed decrease with increasing take-off angle.

In this study, the landing phase of the jump was not recorded by the video camera. However, this omission had no bearing on the conclusions. Precise measurements of the landing height and the 
landing distance were not essential because these parameters had little influence on the optimum takeoff angle. Similarly, precise measurements of the take-off distance were also not essential.

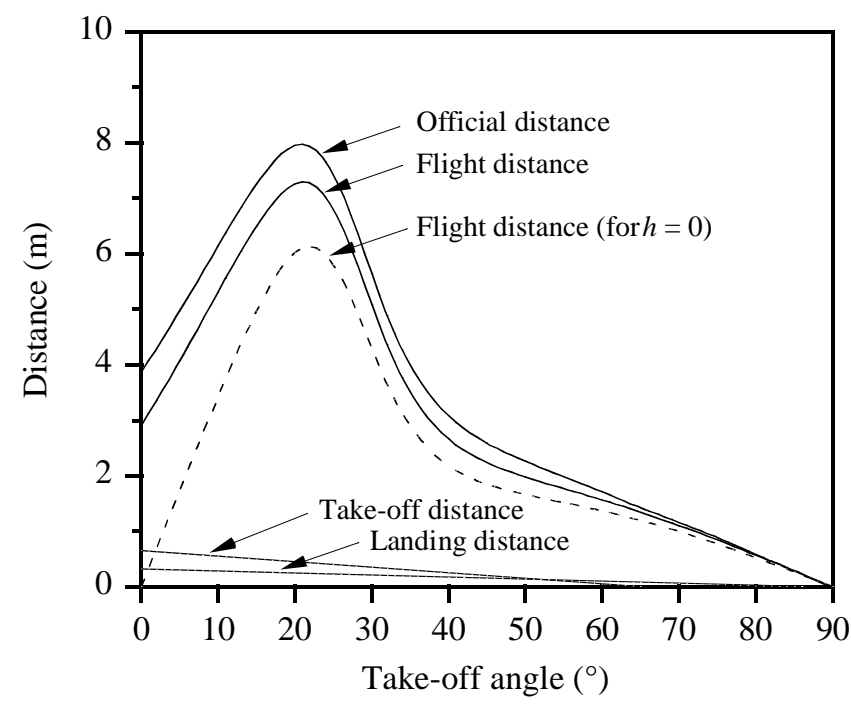

Figure 5. Calculated official distance as a function of take-off angle. The official distance is the sum of the take-off distance, flight distance and landing distance. Also shown is the calculated flight distance, assuming a relative take-off height of $h=0$. The calculated optimum take-off angle for the athlete is about $21^{\circ}$. (Calculations for Athlete 1.)

\section{Discussion}

\section{Sensitivity of performance to take-off angle and take-off speed}

Projecting the body at the optimum take-off angle is important in successful long jumping. The flight distance and official distance are sensitive to take-off angle, and so large errors in take-off angle cannot be tolerated. For the official distance to be within $5 \mathrm{~cm}$ of the maximum achievable distance, the take-off angle must be within about $1^{\circ}$ of the optimum take-off angle (Figure 5). This accuracy is in contrast to the shot put, where a tolerance of about $3^{\circ}$ is allowable for a similar relative loss in performance (Linthorne, 2001).

Although jumping at the optimum take-off angle is important, it is much more important for the athlete to attain a high take-off speed. In this study, distance lost owing to inaccuracies in take-off angle were much less than distance lost owing to variations in take-off speed. When Athlete 1 was jumping at his competition take-off angle, deviations from the calculated optimum take-off angle reduced the official distance by less than $18 \mathrm{~cm}$, whereas inter-trial variations in take-off speed produced changes in official distance of up to $54 \mathrm{~cm}$. Variations in official distance of 10-90 cm have been reported for competition performances by world-class long jumpers (Nixdorf \& Brüggemann, 1988, 1990). These performance variations are probably due to variations in take-off speed caused by inconsistencies in run-up and take-off technique, rather than due to deviations from the optimum take-off angle. 


\section{Practical Applications}

Although this study explains why long jumpers use a take-off angle of just over $20^{\circ}$, the method of determining the optimum take-off angle is unlikely to become a practical diagnostic tool for sports biomechanists and coaches. The method requires a precise determination of the relation between take-off speed and take-off angle, particularly in the range from 0 to $40^{\circ}$. Reliable measurements of this relation are difficult to obtain as the athlete must perform at maximum effort and with good technique over several measurements sessions. For most athletes, a process of trial-and-error at the training track is probably a better method of identifying the athlete's optimum take-off angle. It is likely that the athlete will 'home-in' on their optimum take-off angle relatively quickly with the aid of a tape measure (to measure their performance) and with the guidance of a coach (to help the athlete maintain good technique while experimenting with different take-off angles).

\section{Optimum release angles in the hammer throw and discus throw}

The method used here was previously used to calculate the optimum release angle in the javelin throw (Red \& Zogaib, 1977) and in the shot put (Linthorne, 2001). The method could also be used to predict the optimum release angle in the hammer throw and discus throw. Again, the calculation of the optimum release angle is expected to be dominated by the relation between release speed and release angle, $v(\theta)$. In the hammer throw and discus throw, the flight distance makes a large contribution to the official distance, and so the relations for the relative release height, $h(\theta)$, release distance, $d_{\text {release }}(\theta)$, and landing distance, $d_{\text {landing }}(\theta)$, are expected to have only a small influence on the optimum release angle. To the best of our knowledge there is currently no published data for the relation between release speed and release angle for the hammer throw or for the discus throw. Unfortunately a discus is a highly aerodynamic implement and may not be approximated as a body in free flight (equation 2). Is in the javelin throw, relatively complex equations must be used to describe the trajectory of the implement in the flight phase.

\section{Optimum take-off angle in the high jump and triple jump}

The method used in the present study may also be used to calculate the optimum take-off angle in the high jump. In the high jump the athlete attempts to project their body for maximum vertical height, rather than for maximum horizontal distance. High jump performance is quantified by the official height, $h_{\text {official}}$, which is the height above the ground of the lowest part of the upper surface of the crossbar. The official height may be considered as the sum of the take-off height, $h_{\text {take-off }}$, the flight height, $h_{\text {flight }}$, and the clearance height, $h_{\text {clearance }}$ (Hay, 1993):

$$
h_{\text {official }}=h_{\text {take-off }}+h_{\text {flight }}+h_{\text {clearance }}
$$

The take-off height is the vertical distance between the ground and the athlete's centre of mass at the instant of take-off; the flight height is the vertical distance the athlete's centre of mass travels from 
the instant of take-off to the peak of the jump; and the clearance height is the vertical distance between the crossbar and the athlete's centre of mass at the peak of the jump.

The flight height of a high jumper in free flight is given by (Hay, 1993):

$$
h_{\text {flight }}=\frac{v^{2} \sin ^{2} \theta}{2 g}
$$

where $v$ is the take-off speed, $\theta$ is the take-off angle and $g$ is the acceleration due to gravity. The optimum take-off angle that produces the highest jump may be calculated by combining equation (10) with the measured relation between the take-off speed and take-off angle, $v(\theta)$, for the athlete. The relations between take-off height and take-off angle, $h_{\text {take-off }}(\theta)$, and between clearance height and take-off angle, $h_{\text {clearance }}(\theta)$, are expected to have only a small influence on the optimum take-off angle. To the best of our knowledge, a study to explain the optimum take-off angle in the high jump has not been conducted.

It may be possible to extend the method used in the present study to calculate the optimum takeoff angle in the triple jump. The triple jump is a more complex event than the long jump and high jump in that the athlete executes two additional take-offs. Producing a maximum distance in the hop phase is likely to come at the expense of much reduced distances in the step and jump phases, and hence result in a lesser total jump distance. An experimental determination of the optimum take-off angle in the triple jump therefore requires knowledge of how touchdown speed and angle in one phase affects the take-off speed and angle in the next phase. This appears to be a demanding study.

In conclusion, we have shown that a long jumper's optimum take-off angle may be calculated by combining the equation for the range of a projectile in free flight with the measured relations between the take-off speed, height and angle for the athlete. To achieve good performances, the athlete must jump at close to the optimum take-off angle.

\section{Acknowledgments}

This work was supported by the New South Wales Institute of Sport. Thanks to Keith Connor and Matt Barber for organising the participants, and to Margy Galloway for assistance with filming and biomechanical analysis.

\section{References}

Alexander, R. McN. (1990). Optimum techniques for high and long jumps. Philosophical Transactions of the Royal Society of London: Series B, 329, 3-10.

Arampatzis, A., Brüggemann, G.-P., \& Walsch, M. (1999). Long jump. In: G.-P. Brüggemann, D. Koszewski \& H. Müller (Eds.), Biomechanical Research Project Athens 1997: Final Report,(pp. 82-113). Oxford: Meyer \& Meyer Sport. 
Dapena, J., McDonald, J. \& Cappaert, J. (1990). A regression analysis of high jumping technique. International Journal of Sport Biomechanics, 6, 246-261.

de Mestre, N. (1990). The mathematics of projectiles in sport, Cambridge: Cambridge University Press.

Dempster, W. T. (1955). Space requirements of the seated operator. (WADC-TR-55-159) WrightPatterson Air Force Base, $\mathrm{OH}$.

Graham-Smith, P., \& Lees, A. (1997) A comparison of the information quality between cinematography and videography for long jump analysis. Biology of Sport, 14, 213-225.

Hay, J. G. (1993). The biomechanics of sports techniques (4th edn.). Englewood Cliffs, NJ: PrenticeHall.

Hay, J. G., Miller, J. A., \& Cantera, R. W. (1986). The techniques of elite male long jumpers. Journal of Biomechanics, 19, 855-866.

Hubbard, M. (2001). The flight of sports projectiles. In V. M. Zatsiorsky (Ed.), Biomechanics in sport (pp. 381-400). Oxford: Blackwell Science.

Lees, A., Fowler, N., \& Derby, D. (1993). A biomechanical analysis of the last stride, touchdown, and take-off characteristics of the women's long jump. Journal of Sports Sciences, 11, 303-314.

Lees, A., Graham-Smith, P., \& Fowler, N. (1994). A biomechanical analysis of the last stride, touchdown, and takeoff characteristics of the men's long jump. Journal of Applied Biomechanics, 10, 61-78.

Lichtenberg, D. B., \& Wills, J. G. (1978). Maximizing the range of the shot put. American Journal of Physics, 46, 546-549.

Linthorne, N. P. (2001). Optimum release angle in the shot put. Journal of Sports Sciences, 19, 359372.

Maheras, A. V. (1995). The relationship between the angle of release and the velocity of release in the shot-put, and the application of a theoretical model to estimate the optimum angle of release. Unpublished doctoral dissertation, University of Kansas, Lawrence, KS. Available from University Microfilms, Ann Arbor, MI (AAT 9609510).

Nixdorf, E., \& Brüggemann, P. (1988). Biomechanical analysis of the long jump. In Scientific Report on the Second IAAF World Championships in Athletics (2nd edn., pp. E1-E54). Monaco: International Athletic Foundation.

Nixdorf, E. and Brüggemann, G-P. (1990). Biomechanical analysis of the long jump. In G.-P. Brüggemann and B. Glad (Eds.), Scientific Research Project at the Games of the XXIVth Olympiad - Seoul 1988 Final Report (pp. 263-301). Monaco: International Athletic Foundation.

Press, W. H., Flannery, B. P., Teukolsky, S. A., \& Vetterling, W. T. (1988). Numerical recipes in C : The art of scientific computing. Cambridge, NY: Cambridge University Press. 
Red, W. E., \& Zogaib, A. J. (1977). Javelin dynamics including body interaction. Journal of Applied Mechanics, 44, 496-498.

Tan, A., \& Zumerchik, J. (2000). Kinematics of the long jump. The Physics Teacher, 38, 147-149.

Taylor, J. R. (1997). An introduction to error analysis: The study of uncertainties in physical measurement (2nd edn.). Sausalito, CA: University Science Books.

Wakai M., \& Linthorne N. P. (2002) Optimum takeoff angle in the standing long jump. In S. Ujihashi \& S. J. Haake (Eds.), The Engineering of Sport 4: Proceedings of the 4th International Conference on the Engineering of Sport (pp. 817-823). Oxford: Blackwell Science.

Ward-Smith, A. J. (1985). The influence on long jump performance of the aerodynamic drag experienced during the approach and aerial phases. Journal of Biomechanical Engineering, 107, 336-340.

Winter, D. A. (1990). Biomechanics and motor control of human movement (2nd edn.). New York: John Wiley. 